\title{
Assessment of postoperative pain management and comparison of effectiveness of pain relief treatment involving paravertebral block and thoracic epidural analgesia in patients undergoing posterolateral thoracotomy
}

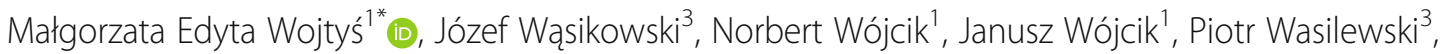

Piotr Lisowski ${ }^{2}$ and Tomasz Grodzki ${ }^{1}$

\begin{abstract}
Background: TEA (thoracic epidural analgesia) is considered a basic method of analgesia used in thoracic surgeries. PVB (paravertebral block) is an alternative method. The thesis compares effectiveness of both methods in postoperative analgesia with particular focus on assessment of the postoperative pain management quality.

Methods: The study involved 2 groups of patients, each consisting of 30 patients undergoing posterolateral thoracotomy. The study group involved patients anesthetized applying PVB method, while the control group involved patients anesthetized with TEA. Hemodynamic and respiratory parameters as well as severity of pain assessed using NRS (numeric rating scale) during the first 3 days after the surgery, number of days of hospitalization, and the need to use additional pain relievers were taken into account in both groups. Evaluation of postoperative pain management quality was performed applying Clinical Quality Indicators in Postoperative Pain Management.
\end{abstract}

Results: No statistical significance was demonstrated between the groups in respect of hemodynamic and respiratory parameters values, the need to use additional pain relievers and the number of days of hospitalization. There was no statistically significant difference between the groups in respect of general assessment of pain management quality, except for the assessment of the lowest level of pain within the last $24 \mathrm{~h}$ of measurement. This result in TEA group was statistically significantly lower than the one in PVB group $(p=0.019)$.

Conclusions: In the assessment of postoperative pain management quality both analyzed methods are statistically significantly different only in the category of "lowest level of pain within the last 24 hours of measurement", to the benefit of TEA group. No statistically significant difference has been observed between the two study groups with respect to the remaining parameters.

Trial registration: KB-0012/71/15. Date of registration 22 June 2015.

Keywords: Regional analgesia, Posterolateral thoracotomy, Assessment of pain management quality, Epidural analgesia, Paravertebral block

\footnotetext{
* Correspondence: margaretkaw@wp.pl

'Department of Thoracic Surgery and Transplantation, Pomeranian Medical

University, Szczecin, Poland

Full list of author information is available at the end of the article
}

(c) The Author(s). 2019 Open Access This article is distributed under the terms of the Creative Commons Attribution 4.0 International License (http://creativecommons.org/licenses/by/4.0/), which permits unrestricted use, distribution, and reproduction in any medium, provided you give appropriate credit to the original author(s) and the source, provide a link to the Creative Commons license, and indicate if changes were made. The Creative Commons Public Domain Dedication waiver (http://creativecommons.org/publicdomain/zero/1.0/) applies to the data made available in this article, unless otherwise stated. 


\section{Background}

Thoracotomy is a type of a surgery that involves one of the most perceptible pains during the postoperative period [1]. Pain after the chest surgery usually lasts approximately 72-96 hours and is more severe than pain after the surgeries of other body areas. This is related, among others, to the fact that the chest is moving as a whole, so it also involves the operated area [2]. Pain after the thoracic surgeries decreases diaphragmatic and other respiratory muscles function, leading to respiratory disorders, including hypoxia, pulmonary infections and cardiologic complications $[1,3]$.

Due to the fact that during posterolateral thoracotomy numerous layers of the chest wall are being cut and dissected, and the dissection takes place within the lung itself and its components (bronchial tubes, vessels, nerves), there are many sources and mechanisms of the post-thoracotomy pain. This not only results from nociceptive mechanisms, but also involves neuropathic component resulting from minor or larger damage to intercostal nerves or other nerves during the surgery. Pulling of visceral or vagus nerves as well as the presence of drain in the pleural cavity after the operative procedure also cause the sensation of pain [4]. Methods involving regional analgesia are often used in treatment of pain post thoracotomy and post thoracoscopic surgeries.

Thoracic epidural analgesia (TEA) is commonly used. The use of the thoracic epidural analgesia in the case of thoracic surgical procedures reduces the stress response to a surgical injury; it favorably affects systemic homeostasis in respect of hormonal response, functions of the immune, coagulation and alimentary system. Epidural analgesia may be accompanied by adverse reactions such as hypotonia, urine retention, respiratory muscles weakness. Other possible complications include epidural abscess, hematoma in the epidural area. In extreme cases, it may result in paraplegia due to damage to the spinal cord, what is observed extremely rarely (below 0.02\%) $[1,3,5]$. TEA or other methods of regional analgesia are also used, among others, in the case of operations involving the thoracic glands, post vertebral column stabilization procedures or urologic operations [6-8].

There are quite numerous contraindications to TEA, such as clotting disturbances caused by intake of anticoagulant medications (e.g. Low Molecular Weight Heparin, Clopidogrel). If a patient is treated with Low Molecular Weight Heparin, epidural block may be performed after 12 hours of heparin administration. According to some authors, TEA is ineffective in more than $12 \%$ of patients, in particular in the case of difficult anatomic conditions [3].

Paravertebral block (PVB) within the chest area is considered an alternative method to TEA, among others, in the case of contraindications to TEA. PVB enables analgesia of the chest only on the side being operated, and the analgesia involves only the area of surgical wound and additionally few segments above and few below the wound, depending on the volume of the regional analgesic agent injected $[9,10]$.

To reach higher precision, ultrasonography control or nerves stimulation are more often used while applying the paravertebral block $[3,11]$. The block can also be applied intraoperatively under direct vision. PVB is contraindicated in the case of difficult anatomic conditions, or infection in the area of planned block application [3]. Blood clotting disturbances do not constitute a contraindication to paravertebral block [8].

Other methods of regional analgesia, such as intercostal block or intrapleural administration of pain relievers are also applied [4].

Although PVB was belived as effective on pain relief as TEA, there are limited evidence on postoperative analgesia for posterolateral thoracotomy. In this study, we goaled to compare the effectiveness between TEA and PVB by measuring numeric pain rating scale (NRS) and clinical quality index (CQI) during the first 3 postoperative days.

Primary purposes of the study involved:

1. Comparison of the effectiveness of PVB and TEA in treatment of postoperative pain in patients undergoing posterolateral thoracotomy.

2. Assessment of postoperative pain management quality based on Clinical Quality Indicators in Postoperative Pain Management in patients who underwent posterolateral thoracotomy and were treated with PVB or TEA.

\section{Methods}

Informed consent to participate in the study was obtained from each patient. Patients were provided with detailed description of benefits, side effects and complications related to both types of analgesia. Ethics Committee of the Pomeranian Medical University in Szczecin approved the study conduct (KB-0012/71/15).

All surgeries were performed applying 10-12 cm long thoracotomy without the use of VATS at one Department of Thoracic Surgery, as consecutive cases. Operations in both groups had similar scope - from tumor resection through segmentectomy, lobectomy through pneumonectomy.

The study involved two groups of patients, each consisting of 30 patients of both sexes, above 18 years of age. Patients were randomized to particular groups (simple randomization). Patients from both groups had no contraindications to application of any of the postoperative analgesia methods. 
Group 1 involves patients who had PVB, while group 2 involves patients who were treated with TEA

\section{Paravertebral block (PVB)}

PVB was performed in the case of patients premedicated with $7.5 \mathrm{mg}$ oral midazolam. It was performed in sitting position, according to slightly modified technique provided for by Cousin and Bridenbaugh [12]. Epidural catheter was placed in the paravertebral area at the level of the lower edge of the spinous process Th4/Th5 ca. 2.5 $\mathrm{cm}$ laterally from the spinous process, depending on the planned surgical incision. Catheter was placed in the paravertebral area at a depth of 3-4 $\mathrm{cm}$. Thereafter, $0.5 \%$ bupivacaini in the total volume from 15 to $25 \mathrm{ml}$ was injected prior to analgesia induction. After completion of the procedure, patients were given additional $15 \mathrm{ml}$ of $0.25 \%$ bupivacaini. After being transferred to the department of thoracic surgeries the patients were given continuous infusion of $0.25 \%$ bupivacaini at the dose of 0.1 $\mathrm{ml}$ per kilogram of body weight (5-8 $\mathrm{ml}$ per hour).

\section{Thoracic epidural analgesia (TEA)}

The second group involved patients who, prior to the posterolateral thoracotomy, were given epidural analgesia performed in the sitting position applying the "hanging drop" technique at the level of Th5/Th6 in the medial body line. Upon identification of the epidural area, an epidural catheter was inserted through Tuohy needle about 4 to $5 \mathrm{~cm}$ into the epidural space. Thereafter, test dose of $2 \mathrm{ml}$ of $1 \%$ lidocaine was injected to exclude spinal anesthesia. Then from 6 to $8 \mathrm{ml}$ of $0.5 \%$ bupivacaini with $0.05 \mathrm{mg}$ of fentanyl was injected. Analgesia induction (in the case of both groups of patients) involved intravenous injection of propofol at the dose of $2 \mathrm{mg}$ per kilogram of the body weight, fentanyl $0.1 \mathrm{mg}$, cisatracurium at the dose of $0.15 \mathrm{mg}$ per kilogram of the body weight. Patients were intubated with two-channel tube. Analgesia was maintained with respiratory mixture of sevoflurane, nitrous oxide and oxygen in commonly used concentrations. Upon completion of the procedure, patients were additionally given $6-8 \mathrm{ml}$ of $0.5 \%$ bupivacaini to epidural catheter. After being transferred to the Department of Thoracic Surgery the patients were given continuous infusion of $0.125 \%$ bupivacaini in the volume of $0.1 \mathrm{ml}$ per kilogram of the body weight $(6-8 \mathrm{ml}$ per hour) and fentanyl at the dose of 2 micrograms per $\mathrm{ml}$ for 72 hours.

All patients were administered nasal oxygen with the flow of 3 liters per minute, for 24 hours. Patients were provided with continuous monitoring of vital signs: saturation $(\mathrm{SpO} 2)$, systolic and diastolic blood pressure, pulse, number of breaths, consciousness.

Patients from each of the groups underwent posterolateral thoracotomy and resection of pulmonary parenchyma mainly due to lung tumor, but also due to the presence of emphysematous bulla, diagnosed based on the typical diagnostic methods, the same for both groups.

Patients qualified to the study were randomized to particular groups (simple randomization).

Exclusion criteria included: failure to obtain the patient's consent, clotting disturbances making it impossible to perform regional analgesia, infection in the area of planned catheter insertion, significant spinal column deformation, difficulties with proper pain severity assessment and T4-infiltrating tumors with continuous pain.

The study was performed in each of the groups according to the same schedule. Measurements had been performed for first three days after the procedure.

Each group had evaluations of $\mathrm{SpO} 2$ every 4 hours, arterial blood pressure and pulse every 4 hours, assessment of pain (NRS) every 4 hours, anesthetized area every 4 hours, the use of additional pain relievers, Clinical Quality Indicators in Postoperative Pain Management.

Values regarding current pain in NRS scale (0-10 pints), the highest level of pain within the last 24 hours (0-10 pints), the lowest level of pain within the last 24 hours (0-10 pints) were marked on the linear scale in the same intervals in the scale of $0-10$ points. Satisfaction with the manner of postoperative pain management was assessed using the scale of 1-10 points.

Clinical Quality Indicators in Postoperative Pain Management scale was used to assess satisfaction with postoperative pain relieving treatment and quality of the postoperative pain management.

Clinical Quality Indicators in Postoperative Pain Management scale allows to assess satisfaction with postoperative pain relieving treatment and quality of the postoperative pain management, however Visual Analog Scale (VAS) and Numeric Pain Rating Scale (NRS) are the simplest and most often used to assess pain. Clinical Quality Indicators in Postoperative Pain Management, a scale developed by Swedish author, Eva Idvall, enables assessment of many various aspects of postoperative pain management quality [13]. This scale was most of all developed to assess satisfaction with nursing care, but is also used to perform general assessment of postoperative pain management quality. It was translated, among others, to Polish and adopted to local conditions. Assessment with the use of Clinical Quality Indicators in Postoperative Pain Management scale is performed according to 5-point Likert scale, where 1 point means "strongly disagree", and 5 points mean "strongly agree". This scale involves also assessment of the highest and the lowest level of pain during the postoperative period within the last 24 hours, assessment of current postoperative pain, similarly to NRS (in the scale of 0-10), assessment of general satisfaction with postoperative pain management in the scale of 1-10 [14]. 
Anesthetized area, i.e. extent of the sensory blockade, was determined based on the number of anesthetized spinal segments according to the anatomic scheme.

Collected data was subject to statistical analysis performed with the use of SPSS package (SPSS Inc., Chicago IL, USA).

T-test for dependent groups and Mann-Whitney U test were used in statistical analysis. Statistical calculations were performed applying the statistical significance of 0.05 .

\section{Results (Table 1)}

The studied groups have not demonstrated statistically significant difference in terms of age and sex $-p=0.74$ and $p=0.58$, respectively.

In the first group indication for surgery constituted: in the case of 14 patients - primary lung cancer, in the case of 4 patients - metastatic tumors, in the case of 3 patients - pleural mesothelioma, while in the case of 9 persons non-neoplastic diseases, such as recurrent spontaneous pneumothorax, benign tumors, pulmonary tuberculosis. In the second group primary lung cancer constituted indication for thoracotomy in the case of 11 persons, metastatic tumors in 4 patients, mediastinal tumors in 2 patients, while non-neoplastic diseases in 13 persons.

In the first group 11 lobectomies, 2 bilobectomies, 1 pneumonectomy, 2 segmentectomies, 7 tumor resections and 6 other surgeries (e.g. explorative thoracotomy, decortication, pleurectomy) were performed.

In the second group 7 lobectomies, 6 segmentectomies, 11 tumor resections and 6 other surgeries, such as decortication, explorative thoracotomy were performed. Range of mesothelioma operations were similar to the decortications or pleurectomy for non-neoplastic diseases.

Results of hemodynamic parameters measurements in the study group presents Table 2 .

Tables 3, 4 and 5 present differences in values of arterial blood pressure, pulse and saturation on particular days of measurements in PVB and TEA groups, and in both groups altogether.

Table 6 presents comparison of other tested parameters in PVB and TEA groups.

\section{Additional pain relievers}

There were additional pain relievers (morphine, metamizole, ketoprofen, paracetamol) with basic analgesia method (PVB or TEA), while in the case of some patients combination of these drugs was used (Table 7).

Morphine and other pain relievers, such as paracetamol or ketoprofen were used more often in PVB group, while metamizole was more often used in TEA group; however, there was no statistical difference in terms of the use of additional pain relievers between the groups.

\section{Complications}

Complications were observed in 11 persons (18.3\%). In 4 persons (13.3\%) from the PVB group, and in 7 persons (23.3\%) from the TEA group. The difference between the groups was not statistically significant $(p=0.32)$. Leaking of regional analgesia medications outside the epidural catheter, catheter coming out from the paravertebral area, fever, retention of secretion in the respiratory tract, respiratory failure have been observed in PVB group. In the TEA group complications included, among others, retention of secretion in the respiratory tract, paroxysmal atrial fibrillation.

Partial spinal anesthesia with symptoms of paraplegia involving all body segments from Th4 downwards, was observed in one patient from TEA group. The patient has not lost consciousness or respiratory efficiency, because upon occurrence of the first symptoms of spinal anesthesia "epidural" infusion of $0.125 \%$ bupivacaini was stopped and the epidural catheter was removed. Symptoms of spinal anaesthesia resolved within four hours. MRI of thoracic spine was performed. No damage to the spinal cord was observed. No neurological consequences have been observed in the patient. Upon completion of the treatment, the patient was discharged home in good general condition.

\section{Pain severity assessment}

\section{Pain severity assessment using NRS}

Groups were compared in terms of pain severity using NRS on three days after the surgery; results are presented in Table 8.

No statistically significant differences in NRS values between PVB and TEA groups have been observed on three subsequent days after the surgery.

Table 1 Demographic data of the study groups

\begin{tabular}{llll}
\hline Group & PVB - group 1 - number (\%) & TEA- group 2 -number (\%) & Total number (\%) \\
\hline Age in years number of persons (\%) & & $5(16.7)$ & $8(13.3)$ \\
$20-50$ & $3(10)$ & $19(63.3)$ & $40(66.7)$ \\
$51-70$ & $21(70)$ & $6(20)$ & $12(20)$ \\
Above 70 & $6(20)$ & $19 / 11(63.3 / 36.7)$ & $40 / 20(66.7 / 33.3)$ \\
Sex M/F & $21 / 9(70 / 30)$ &
\end{tabular}


Table 2 Hemodynamic parameters: blood pressure (systolic (s) and diastolic (d)), pulse, arterial oxygen saturation as well as number of days of hospitalization in particular (PVB, TEA) groups during 3 days after surgery

\begin{tabular}{|c|c|c|c|c|c|c|c|c|c|c|c|c|c|}
\hline & \multicolumn{11}{|l|}{ Group } & \multirow{3}{*}{$\begin{array}{l}\text { Mann-Whitney } \\
\text { U test }\end{array}$} & \multirow[t]{3}{*}{$P$} \\
\hline & \multicolumn{3}{|l|}{ PVB } & \multicolumn{3}{|l|}{ TEA } & \multicolumn{5}{|l|}{ Total } & & \\
\hline & $\overline{M e a n}$ & $\mathrm{~N}$ & $\begin{array}{l}\text { Standard } \\
\text { deviation }\end{array}$ & Mean & $\mathrm{N}$ & $\begin{array}{l}\text { Standard } \\
\text { deviation }\end{array}$ & Mean & $\mathrm{N}$ & $\begin{array}{l}\text { Standard } \\
\text { deviation }\end{array}$ & Minimum & Maximum & & \\
\hline $\begin{array}{l}\text { a blood pressure-s- (every } 4 \mathrm{~h} \text { ) } \\
1 \text { st day }\end{array}$ & 122.10 & 30 & 11.25 & 119.13 & 30 & 13.50 & 120.62 & 60 & 12.41 & 98.00 & 148.00 & 360.50 & .186 \\
\hline $\begin{array}{l}\text { b blood pressure-d- (every } 4 \mathrm{~h} \text { ) } \\
\text { 1st day }\end{array}$ & 69.30 & 30 & 8.89 & 66.83 & 30 & 7.64 & 68.07 & 60 & 8.31 & 53.00 & 87.00 & 369.50 & .233 \\
\hline a blood pressure-s- (every $4 \mathrm{~h}$ ) & 122.37 & 30 & 13.31 & 120.00 & 30 & 16.43 & 121.18 & 60 & 14.87 & 88.00 & 156.00 & 386.00 & .344 \\
\hline \multicolumn{14}{|l|}{ 2nd day } \\
\hline b blood pressure-d- (every $4 \mathrm{~h}$ ) & 70.07 & 30 & 10.79 & 67.47 & 30 & 7.64 & 68.77 & 60 & 9.36 & 48.00 & 87.00 & 386.00 & .344 \\
\hline \multicolumn{14}{|l|}{ 2nd day } \\
\hline $\begin{array}{l}\text { a blood pressure-s- (every } 4 \mathrm{~h} \text { ) } \\
\text { 3rd day }\end{array}$ & 129.17 & 24 & 15.96 & 123.91 & 23 & 12.92 & 126.60 & 47 & 14.64 & 101.00 & 160.00 & 242.00 & .469 \\
\hline $\begin{array}{l}\text { b blood pressure-d- (every } 4 \mathrm{~h} \text { ) } \\
\text { 3rd day }\end{array}$ & 72.50 & 24 & 10.16 & 72.09 & 23 & 8.81 & 72.30 & 47 & 9.42 & 55.00 & 89.00 & 273.50 & .957 \\
\hline pulse 1st day & 81.80 & 30 & 10.53 & 79.93 & 30 & 10.76 & 80.87 & 60 & 10.59 & 56.00 & 104.00 & 408.00 & .534 \\
\hline pulse 2nd day & 84.07 & 30 & 8.63 & 84.56 & 30 & 10.07 & 84.31 & 60 & 9.30 & 64.00 & 105.00 & 443.50 & .923 \\
\hline pulse 3rd day & 84.04 & 24 & 9.93 & 85.09 & 23 & 9.83 & 84.55 & 47 & 9.79 & 66.00 & 108.00 & 262.00 & .765 \\
\hline $\mathrm{SaO} 2$ 1st day & 97.62 & 29 & 1.99 & 97.01 & 30 & 1.62 & 97.31 & 59 & 1.82 & 92.00 & 100.00 & 328.50 & .102 \\
\hline $\mathrm{SaO} 2$ 2nd day & 95.18 & 17 & 2.30 & 95.20 & 20 & 2.50 & 95.19 & 37 & 2.38 & 90.00 & 100.00 & 160.00 & .758 \\
\hline $\mathrm{SaO} 2$ 3nd day & 95.71 & 7 & 0.95 & 95.13 & 8 & 2.85 & 95.40 & 15 & 2.13 & 90.00 & 99.00 & 23.50 & .595 \\
\hline $\begin{array}{l}\text { number of days of hospitalization } \\
\text { after surgery }\end{array}$ & 7.47 & 30 & 3.70 & 6.30 & 30 & 1.95 & 6.88 & 60 & 2.99 & 3.00 & 23.00 & 354.00 & .150 \\
\hline
\end{tabular}

NRS values measured every 4 hours have been compared for both groups altogether and for each of the groups separately.

On the first day NRS value for both groups altogether was 4.13 with standard deviation of 1.28 ; on the second day 3.08 with standard deviation of 1.08 , and on the third day 2.46 with standard deviation of 1.15 . For both groups altogether, NRS values on the first day compared to the values obtained on the second day and values obtained on the first day compared to the values obtained on the third day, as well as values obtained on the second day compared to the values obtained on the third day were statistically significantly lower $(p=0.00)$.

While comparing NRS values in the PVB group, on the first and the second day and on the first and the third day, as well as on the second and on the third day, statistically significant decreasing of NRS values has been observed, $p=0.000, p=0.000$ and $p=0.008$, respectively.

While comparing NRS values in the TEA group, on the first and the second day and on the first and the third day, as well as on the second and on the third day, statistically significant decreasing of NRS values has been observed, $p=0.001, p=0.000$ and $p=0.001$, respectively.
No statistically significant differences in assessment of particular statements in both groups have been observed, except for the assessment of the lowest level pain within the last $24 \mathrm{~h}(p=0,019)$.

Table 9 presents results obtained in particular groups in Clinical Quality Indicators in Postoperative Pain Management scale and comparison of both groups.

\section{Discussion}

Methods of regional analgesia are often used in treatment of pain after the chest area surgeries. Currently, TEA is the method of choice. Even though it is considered the method of choice it has many contraindications and side effects. Alternative method of local analgesia in thoracic surgeries is PVB above all [15]. Many authors consider PVB a method with similar effectiveness in pain management to TEA, but with more beneficial side effects profile $[10,16,17]$.

\section{Hemodynamic parameters - arterial blood pressure and heart rate}

Systolic and diastolic pressure on particular three days after the surgery were similar in both groups. Statistically significant increase of systolic and diastolic pressure values between the first and the third day, and the 
Table 3 Results of measurements of arterial blood pressure (systolic (s) and diastolic (d)), pulse, and saturation in both groups on particular days

\begin{tabular}{|c|c|c|c|c|c|c|c|}
\hline \multicolumn{5}{|l|}{ Statistics for dependent groups } & \multirow[t]{2}{*}{ t-test } & \multirow{2}{*}{$\begin{array}{l}\text { Degrees of } \\
\text { freedom }\end{array}$} & \multirow[t]{2}{*}{$p$} \\
\hline $\begin{array}{l}\text { Comparison of hemodynamic parameters between particular } \\
\text { days after surgery in all patients (both groups altogether) }\end{array}$ & Mean & N & Standard deviation & Standard error of the mean & & & \\
\hline a blood pressure-s- (every 4 h) 1st day & 120.62 & 60 & 12.41 & 1.60 & -0.31 & 59 & .761 \\
\hline a blood pressure-s- (every 4 h) 2nd day & 121.18 & 60 & 14.87 & 1.92 & & & \\
\hline a blood pressure-s- (every 4 h) 1st day & 121.15 & 47 & 12.81 & 1.87 & -2.32 & 46 & .025 \\
\hline a blood pressure-s- (every 4 h) 3rd day & 126.60 & 47 & 14.64 & 2.14 & & & \\
\hline a blood pressure-s- (every 4 h) 2nd day & 120.98 & 47 & 15.66 & 2.28 & -2.32 & 46 & .025 \\
\hline a blood pressure-s- (every 4 h) 3rd day & 126.60 & 47 & 14.64 & 2.14 & & & \\
\hline b blood pressure-d- (every 4 h) 1st day & 68.07 & 60 & 8.31 & 1.07 & -0.67 & 59 & .504 \\
\hline b blood pressure-d- (every 4 h) 2nd day & 68.77 & 60 & 9.36 & 1.21 & & & \\
\hline b blood pressure-d- (every 4 h) 1st day & 67.81 & 47 & 8.33 & 1.22 & -3.16 & 46 & .003 \\
\hline b blood pressure-d- (every 4 h) 3rd day & 72.30 & 47 & 9.42 & 1.37 & & & \\
\hline b blood pressure-d- (every 4 h) 2nd day & 68.00 & 47 & 9.85 & 1.44 & -3.04 & 46 & .004 \\
\hline b blood pressure-d- (every 4 h) 3rd day & 72.30 & 47 & 9.42 & 1.37 & & & \\
\hline pulse 1st day & 80.87 & 60 & 10.59 & 1.37 & -3.39 & 59 & .001 \\
\hline pulse 2nd day & 84.31 & 60 & 9.30 & 1.20 & & & \\
\hline pulse 1st day & 80.57 & 47 & 10.26 & 1.50 & -2.76 & 46 & .008 \\
\hline pulse 3rd day & 84.55 & 47 & 9.79 & 1.43 & & & \\
\hline pulse 2nd day & 83.83 & 47 & 9.16 & 1.34 & -0.73 & 46 & .468 \\
\hline pulse 3rd day & 84.55 & 47 & 9.79 & 1.43 & & & \\
\hline $\mathrm{SaO} 2$ 1st day & 97.19 & 37 & 1.69 & 0.28 & 5.40 & 36 & .000 \\
\hline $\mathrm{SaO} 2$ 2nd day & 95.19 & 37 & 2.38 & 0.39 & & & \\
\hline $\mathrm{SaO} 2$ 1st day & 97.40 & 15 & 2.03 & 0.52 & 3.08 & 14 & .008 \\
\hline $\mathrm{SaO} 2$ 3rd day & 95.40 & 15 & 2.13 & 0.55 & & & \\
\hline $\mathrm{SaO} 2$ 2nd day & 94.50 & 10 & 2.55 & 0.81 & -0.85 & 9 & .415 \\
\hline $\mathrm{SaO} 2$ 3rd day & 95.10 & 10 & 2.47 & 0.78 & & & \\
\hline
\end{tabular}

second and the third day, as well as increase in the heart rate values between the first and the second day and the first and the third day has been observed for both groups analysed altogether. Statically significant increase of systolic pressure values between the first and the third day and the second and the third day as well as increase of the diastolic pressure values between the first and the third day have been observed in the PVB group. Statistically significant increase of diastolic pressure values between the first and the third day and the second and the third day after the surgery was observed in the TEA group. There was no statistically significant difference in the mean values of heart activity between particular days after the surgery in PVB group, while in TEA group statistically significant increase of mean values of heart activity has been observed between the first and the second day and the first and the third day after the surgery; however, on particular days after the surgery both groups were not statistically significantly different in respect of heart rate. Egyptian authors observed significant decrease in arterial blood pressure values in TEA group compared to patients treated with PVB. Similarly, Davies et al. and authors from India stated that TEA causes more evident arterial blood pressure decrease compared to PVB, what results from the fact that TEA has a greater impact on sympathetic system compared to PVB $[10,16,18]$. Studies performed by Szebla et al. also showed non-substantial impact of administration of medicines used for conduction anesthesia to the paravertebral area in the thoracic segment on the basic hemodynamic parameters [19].

\section{Respiratory system functions - arterial blood saturation} Statistically significant decrease in arterial blood saturation between the first and the second day after the surgery and between the first and the third day was observed in the PVB group. Statistically significant decrease in saturation in TEA group was observed between the first and the second day after the surgery. On respective days the groups showed no statistically significant difference in 
Table 4 Results of measurements of arterial blood pressure (systolic (s) and diastolic (d) ), pulse, and saturation in PVB group on particular days

\begin{tabular}{|c|c|c|c|c|c|c|c|}
\hline \multicolumn{5}{|l|}{ Statistics for dependent groups } & \multirow[t]{2}{*}{ t- test } & \multirow{2}{*}{$\begin{array}{l}\text { Degrees of } \\
\text { freedom }\end{array}$} & \multirow[t]{2}{*}{$p$} \\
\hline $\begin{array}{l}\text { Comparison of hemodynamic parameters between } \\
\text { particular days after surgery in PVB group }\end{array}$ & Mean & $\mathrm{N}$ & Standard deviation & $\begin{array}{l}\text { Standard error } \\
\text { of the mean }\end{array}$ & & & \\
\hline a blood pressure-s- (every 4 h) 1st day & 122.10 & 30 & 11.25 & 2.05 & -0.10 & 29 & .924 \\
\hline a blood pressure-s- (every 4 h) 2nd day & 122.37 & 30 & 13.31 & 2.43 & & & \\
\hline a blood pressure-s- (every 4 h) 1st day & 121.92 & 24 & 11.06 & 2.26 & -2.13 & 23 & .044 \\
\hline a blood pressure-s- (every 4 h) 3rd day & 129.17 & 24 & 15.96 & 3.26 & & & \\
\hline a blood pressure-s- (every 4 h) 2nd day & 121.33 & 24 & 13.80 & 2.82 & -2.17 & 23 & .041 \\
\hline a blood pressure-s- (every 4 h) 3rd day & 129.17 & 24 & 15.96 & 3.26 & & & \\
\hline b blood pressure-d- (every 4 h) 1st day & 69.30 & 30 & 8.89 & 1.62 & -0.46 & 29 & .650 \\
\hline b blood pressure-d- (every 4 h) 2nd day & 70.07 & 30 & 10.79 & 1.97 & & & \\
\hline b blood pressure-d- (every 4 h) 1st day & 68.38 & 24 & 8.83 & 1.80 & -2.05 & 23 & .050 \\
\hline b blood pressure-d- (every 4 h) 3rd day & 72.50 & 24 & 10.16 & 2.07 & & & \\
\hline b blood pressure-d- (every 4 h) 2nd day & 68.88 & 24 & 11.13 & 2.27 & -1.87 & 23 & .075 \\
\hline b blood pressure-d- (every 4 h) 3rd day & 72.50 & 24 & 10.16 & 2.07 & & & \\
\hline pulse 1st day & 81.80 & 30 & 10.53 & 1.92 & -1.54 & 29 & .136 \\
\hline pulse 2nd day & 84.07 & 30 & 8.63 & 1.58 & & & \\
\hline pulse 1st day & 81.17 & 24 & 10.38 & 2.12 & -1.37 & 23 & .183 \\
\hline pulse 3rd day & 84.04 & 24 & 9.93 & 2.03 & & & \\
\hline pulse 2nd day & 84.21 & 24 & 8.09 & 1.65 & 0.13 & 23 & .896 \\
\hline pulse 3rd day & 84.04 & 24 & 9.93 & 2.03 & & & \\
\hline $\mathrm{SaO} 2$ 1st day & 97.28 & 17 & 1.83 & 0.44 & 3.86 & 16 & .001 \\
\hline $\mathrm{SaO} 2$ 2nd day & 95.18 & 17 & 2.30 & 0.56 & & & \\
\hline $\mathrm{SaO} 2$ 1st day & 97.94 & 7 & 2.04 & 0.77 & 4.44 & 6 & .004 \\
\hline $\mathrm{SaO} 2$ 3rd day & 95.71 & 7 & 0.95 & 0.36 & & & \\
\hline $\mathrm{SaO} 2$ 2nd day & 94.75 & 4 & 3.20 & 1.60 & -0.42 & 3 & .703 \\
\hline $\mathrm{SaO} 2$ 3rd day & 95.25 & 4 & 0.96 & 0.48 & & & \\
\hline
\end{tabular}

respect of saturation values changes. For both groups altogether, statistically significant decrease in saturation values were observed between the first and the second day and the first and the third day after the surgery. These observations differ from the ones of Richardson et al. (Richardson et al., 1999), where saturation in PVB group was significantly higher in the follow-up period exceeding 48 hours than in the case of TEA group [9].

\section{Additional pain relievers}

Additional pain relievers were used in both study groups. Morphine, metamizole and other pain relievers, mainly acetaminofen or ketoprofen, were used in the same administration.

In the case of PVB group morphine was twice as likely often and medicines from other groups were slightly less often used compared to TEA group, while metamizole was more often used in TEA group compared to PVB group. No statistically significant differences have been observed between the groups in terms of the need to use additional pain relievers; however, patients from PVB group needed them a bit more often. Authors from India have similar observations - their study showed no statistically significant difference in terms of use of Morphine (it was the only one additional drug) between PVB and TEA groups [18]. In the study conducted by Messina et al., morphine was statistically significantly more often used in PVB group than in TEA group, while in the study performed by Pintarica et al., the need to use morphine was similar in PVB and TEA groups [20,21]. Similarly, the study conducted by Okajima et al. showed no statistically significant difference in terms of use of additional pain relievers between PVB and TEA group ( $p=$ 0.26) [11]. In the study conducted by Komatsu, $17.6 \%$ of patients who were treated with PVB needed additional pain relievers [22]. 
Table 5 Results of measurements of arterial blood pressure (systolic (s) and diastolic (d) ), pulse, and saturation in TEA group on particular days

\begin{tabular}{|c|c|c|c|c|c|c|c|}
\hline \multicolumn{5}{|l|}{ Statistics for dependent groups } & \multirow[t]{2}{*}{ t-test } & \multirow{2}{*}{$\begin{array}{l}\text { Degrees of } \\
\text { freedom }\end{array}$} & \multirow[t]{2}{*}{$\mathrm{p}$} \\
\hline $\begin{array}{l}\text { Comparison of hemodynamic parameters between } \\
\text { particular days after surgery in TEA group }\end{array}$ & Mean & $\mathrm{N}$ & Standard deviation & $\begin{array}{l}\text { Standard error } \\
\text { of the mean }\end{array}$ & & & \\
\hline a blood pressure-s- (every 4 h) 1st day & 119.13 & 30 & 13.50 & 2.47 & -0.34 & 29 & .734 \\
\hline a blood pressure-s- (every 4 h) 2nd day & 120.00 & 30 & 16.43 & 3.00 & & & \\
\hline a blood pressure-s- (every 4 h) 1st day & 120.35 & 23 & 14.63 & 3.05 & -1.10 & 22 & .284 \\
\hline a blood pressure-s- (every 4 h) 3rd day & 123.91 & 23 & 12.92 & 2.69 & & & \\
\hline a blood pressure-s- (every 4 h) 2nd day & 120.61 & 23 & 17.71 & 3.69 & -1.03 & 22 & .314 \\
\hline a blood pressure-s- (every 4 h) 3rd day & 123.91 & 23 & 12.92 & 2.69 & & & \\
\hline b blood pressure-d- (every 4 h) 1st day & 66.83 & 30 & 7.64 & 1.40 & -0.50 & 29 & .622 \\
\hline b blood pressure-d- (every 4 h) 2nd day & 67.47 & 30 & 7.64 & 1.40 & & & \\
\hline b blood pressure-d- (every 4 h) 1st day & 67.22 & 23 & 7.94 & 1.65 & -2.37 & 22 & .027 \\
\hline b blood pressure-d- (every 4 h) 3rd day & 72.09 & 23 & 8.81 & 1.84 & & & \\
\hline b blood pressure-d- (every 4 h) 2nd day & 67.09 & 23 & 8.46 & 1.76 & -2.39 & 22 & .026 \\
\hline b blood pressure-d- (every 4 h) 3rd day & 72.09 & 23 & 8.81 & 1.84 & & & \\
\hline pulse 1st day & 79.93 & 30 & 10.76 & 1.96 & -3.33 & 29 & .002 \\
\hline pulse 2nd day & 84.56 & 30 & 10.07 & 1.84 & & & \\
\hline pulse 1st day & 79.96 & 23 & 10.34 & 2.16 & -2.57 & 22 & .018 \\
\hline pulse 3rd day & 85.09 & 23 & 9.83 & 2.05 & & & \\
\hline pulse 2nd day & 83.43 & 23 & 10.32 & 2.15 & -1.07 & 22 & .296 \\
\hline pulse 3rd day & 85.09 & 23 & 9.83 & 2.05 & & & \\
\hline SaO2 1st day & 97.12 & 20 & 1.61 & 0.36 & 3.71 & 19 & .002 \\
\hline $\mathrm{SaO} 2$ 2nd day & 95.20 & 20 & 2.50 & 0.56 & & & \\
\hline $\mathrm{SaO} 2$ 1st day & 96.93 & 8 & 2.03 & 0.72 & 1.53 & 7 & .169 \\
\hline $\mathrm{SaO} 2$ 3rd day & 95.13 & 8 & 2.85 & 1.01 & & & \\
\hline $\mathrm{SaO} 2$ 2nd day & 94.33 & 6 & 2.34 & 0.95 & -0.70 & 5 & .516 \\
\hline $\mathrm{SaO} 2$ 3rd day & 95.00 & 6 & 3.22 & 1.32 & & & \\
\hline
\end{tabular}

\section{Complications}

In our own studies complications were more often observed in TEA group than in PVB group. In PVB group complications were observed in 4 persons, i.e. in $13.3 \%$ of the group, while in TEA group complications were observed in 7 persons, i.e. in 23.3\%; however the difference in respect of frequency of complications between the study groups was not statistically significant. Complications in PVB group were more often related to catheter and included, among others, leaking of drug outside the catheter or catheter coming out, rather than general complications (e.g. decrease in arterial blood pressure).

In TEA group there were no complications such as hematoma or epidural empyema or damage to nerves. Partial spinal anesthesia with symptoms of paraplegia involving all body segments from Th4 downwards was observed in one patient from TEA group. Symptoms of spinal anesthesia resolved within four hours. Many authors, among others Davies et al. or Baidya et al., emphasize that PVB has in general less complications than TEA, what involves less complications

Table 6 Other tested parameters in PVB and TEA groups

\begin{tabular}{|c|c|c|c|c|c|}
\hline Tested parameter & Group PVB & Group TEA & $\mathrm{p}$ & Minimum & Maximum \\
\hline Number of days of hospitalization & 7.47 (SD 3.7) & $6.3(S D 1.95)$ & 0.15 & 3 & 23 \\
\hline Time of surgical procedure expressed in minutes & 91.67 (SD 28.2) & 98.67 (SD 37.87) & 0.646 & 45 & 185 \\
\hline Time of maintaining pleural drain after the surgical procedure expressed in days & $5.13(\mathrm{SD} 4.17)$ & $4.93($ SD 1.84) & 0.736 & 2 & 23 \\
\hline
\end{tabular}


Table 7 Use of additional pain relievers in particular gropus

\begin{tabular}{llll}
\hline Drug (24-h doses) & PVB group & TEA group & $\mathrm{p}$ \\
\hline Morphine (30 mg) & 6 persons (20\%) & 3 persons (10\%) & 0.28 \\
$\begin{array}{l}\text { Other pain relievers } \\
\text { Paracetamol }(4 \mathrm{~g})\end{array}$ & 16 persons (53.3\%) & 9 persons (30\%) & 0.07 \\
Ketoprofen (200 mg) & & & \\
Metamizole (3 g) & 15 persons (50\%) & 22 persons (73.3\%) & 0.06 \\
\hline
\end{tabular}

such as decrease in arterial blood pressure, hypoxia, nausea and vomiting or postoperative respiratory failure or pneumonia $[1,10]$. Japanese authors in their studies involving patients treated with PVB observed, among others, such complications as atrial fibrillation or respiratory failure requiring mechanical ventilation, but these were single cases [23]. Similarly - also in single cases - occurrence of atrial fibrillation or respiratory failure among the treated patients was observed.

\section{Pain severity assessment}

In the conducted studies we have observed comparable severity of pain in both groups. In the studies conducted by Szebla and Machała, who also used NRS to compare pain in PVB and TEA groups, NRS values in both groups were similar and the result was below 3 [8]. Tsuboshima et al. analyzed pain ailments in patients undergoing thoracoscopic surgeries of idiopathic pneumothorax, who were treated with PVB. Pain ailments were assessed using NRS - average NRS value after 6 hours amounted to 2.3 point, after 24 hours after the surgery it was 2.2 points, and after 48 hours it was 1 point - it was less than in our studies, what could result from the use of minimally invasive method and from the smaller extent of the surgery [24].

Majority of authors assessing postoperative pain uses VAS. In the study conducted by Richardson et al., for example, VAS value was statistically significantly lower in PVB group than in TEA group $(p=0.02)$. While, in the meta-analysis of Ding et al. there were no statistically significant differences in VAS values between PVB and TEA groups at 4-8 hours after the surgery $(p=0.19), 24$ hours after the surgery $(0.77)$ and 48 hours after the surgery $(p=0.19)[3,9]$.

Table 8 Comparison of NRS values in particular groups on three subsequent days after the surgery

\begin{tabular}{llll}
\hline NRS measurements & PVB mean (SD) & TEA mean (SD) & $P$ \\
\hline NRS 1st day & $4.33(1.37)$ & $3.93(1.18)$ & $P=0.206$ \\
NRS 2nd day & $3.05(0.88)$ & $3.11(1.27)$ & $P=0.935$ \\
NRS 3rd day & $2.55(1.06)$ & $2.37(1.25)$ & $P=0.496$ \\
\hline
\end{tabular}

In the study conducted by Japanese authors, there were no differences between PVB and TEA groups in terms of pain ailments assessed using VRS (Verbal Rating Scale) [11].

\section{Number of days of hospitalization}

In the conducted studies it was assessed if the type of regional postoperative analgesia in chest surgeries affects the number of days of the patient's stay at the hospital. Statistically significant difference in the number of days of hospitalization between PVB and TEA groups has not been observed.

However, Elsayed et al. observed statistically significant difference between the time of hospitalization of patients who were treated with PVB compared to TEA patients ( $p=0.008)$ of 1 day ( 6 days vs. 7 days) - time of hospitalization of patients treated with PVB was 1 day shorter and based on this observation they suggested that PVB can become an element of the so called fast track management in chest surgeries. However, this requires further research and improvement of PVB technique [25].

\section{Assessment of patients' satisfaction with pain management}

Assessment of patients' satisfaction with pain management was performed based on the Clinical Quality Indicators in Postoperative Pain Management scale, translated into Polish and adopted to local conditions [13, 14]. Among aspects indicated on the said scale, methods of analgesia being compared in the study, i.e. PVB and TEA, were statistically significantly different only in respect of the category "the lowest level of pain within the last $24 \mathrm{~h}$ " in the scale of 0-10 points. Result in TEA group was statistically significantly lower than the one in PVB group $(p=0.019)$. In the case of other criteria, PVB and TEA groups were not statistically significantly different. In the study conducted by Okajima et al., no statistically significant difference in respect of the general patient's satisfaction with treatment (authors used another scale than the one used in our study) was observed between PVB and TEA group $(p=0.26)$ [11].

\section{Conclusions}

1. PVB and TEA are not significantly different in terms of postoperative pain management and the need to use additional pain relievers.

2. In the assessment of postoperative pain management quality, both analyzed methods are statistically significantly different in favor of TEA only in the category of "the lowest level of pain within the last 24 hours" of the Quality of Indicators in Postoperative Pain Management scale. 


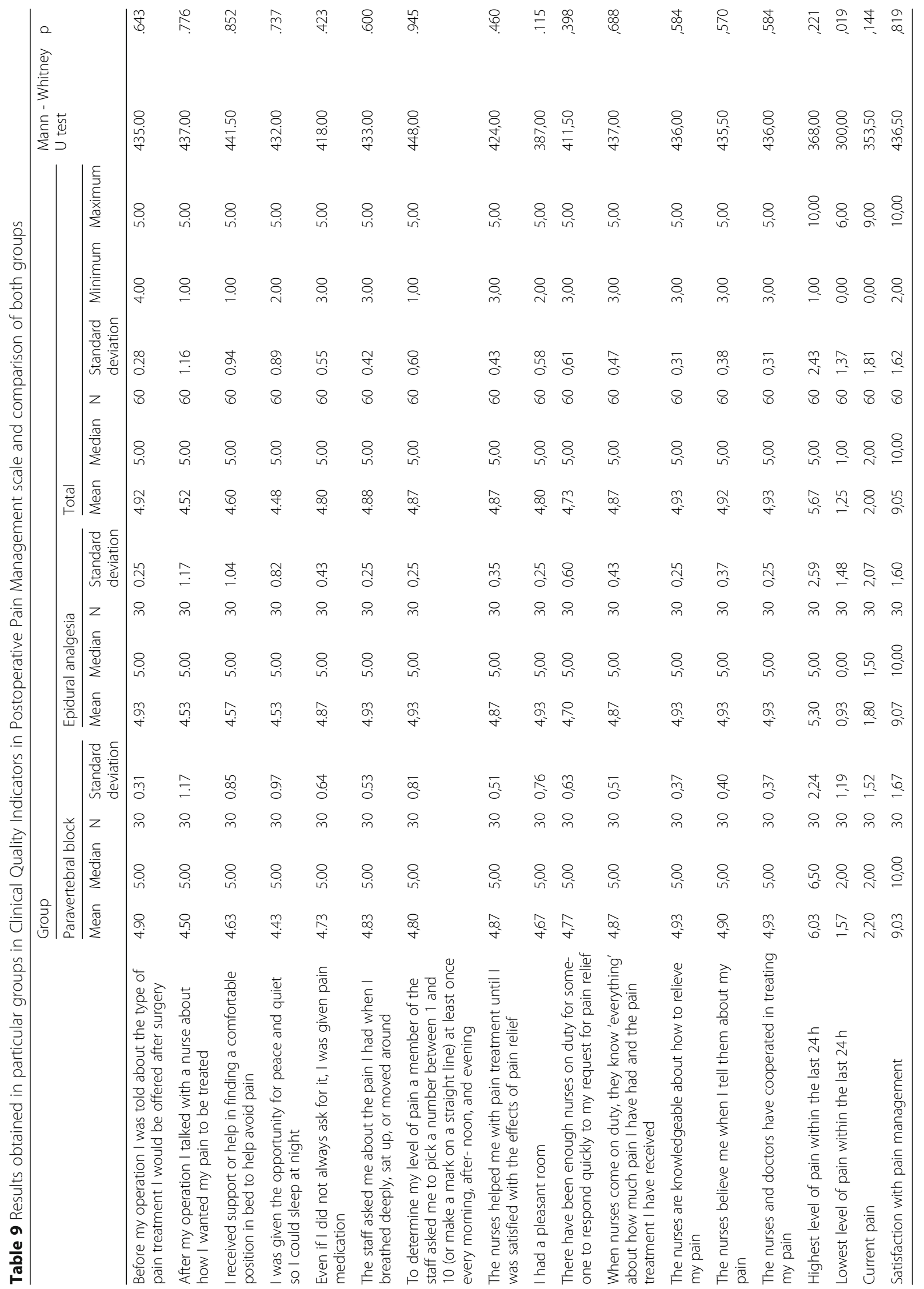


3. No significant differences have been observed in respect of occurrence of complications between the two compared methods.

4. TEA seems to be better in managing pain after thoracotomy on the basis of our results, however both methods are comparable.

\section{Abbreviations}

MRI: Magnetic resonance imaging; NRS: Numeric rating scale;

PVB: Paravertebral block; TEA: Thoracic epidural analgesia; VAS: Visual analog scale; VATS: Video-assisted thoracoscopic surgery

\section{Acknowledgments}

not applicable

\section{Funding}

The study was financed from the founds of the Young Researcher Program of the Pomeranian Medical University

\section{Availability of data and materials}

All data generated or analyzed during this study are included in this published article

\section{Authors' contributions}

MEW - elaboration of the project, conduction of clinical tests, treatment of the obtained results and preparation of the publication. JWąsikowski elaboration of the project, conduction of clinical tests, treatment of the obtained results. NW - conduction of clinical trails, treatment of the obtained results and preparation of the publication. JWójcik - treatment of the obtained results. PW - review of the paper. PL - preparation of the publication. TG - elaboration of the project and the review of the paper. All authors read and approved the final manuscript.

\section{Ethics approval and consent to participate}

Ethics Committee of the Pomeranian Medical University in Szczecin approved the study conduct (KB-0012/71/15).

\section{Consent for publication}

not applicable

\section{Competing interests}

The authors declare that they have no competing interests.

\section{Publisher's Note}

Springer Nature remains neutral with regard to jurisdictional claims in published maps and institutional affiliations.

\section{Author details}

'Department of Thoracic Surgery and Transplantation, Pomeranian Medical University, Szczecin, Poland. 'Students' Scientific Circle of the Department of Thoracic Surgery and Transplantation, Pomeranian Medical University, Szczecin, Poland. ${ }^{3}$ The Department of Anesthesiology and Intensive Therapy, Prof. A. Sokołowski Specialist Hospital, Szczecin, Poland.

Received: 3 October 2018 Accepted: 1 April 2019

Published online: 16 April 2019

\section{References}

1. Baidya D.K., Khanna P., Maitra S.: Analgesic efficacy and safety of thoracic paravertebral and epidural analgesia for thoracic surgery: a systematic review and meta-analysis. Interact Cardiovasc Thorac Surg. 2014;18:626-36.

2. Rzechonek A., Kołodziej J., Majewski A.M., Kacprzak G., Pawlak I., Spytkowski L.: Ból po torakotomii- analiza zjawiska, nowa forma jego oceny i przebiegu. W Wybrane zagadnienia z chirurgii klatki piersiowej. Wyd Polski Przegląd Chirurgiczny; 1996:313-27.

3. Ding X., Jin S., Niu X., Ren H., Fu S., Li Q.: A comparison of the analgesia efficacy and side effects of paravertebral compared with epidural blockade for thoracotomy: an updated meta-analysis. PLoS One. 2014;9:1-9.
4. Kolettas A., Lazaridis G., Baka S., Mpoukovinas I., Karavasilis V., Kioumis I., et al.: Postoperative pain management. J Thorac Dis. 2015;7:S62-72.

5. Kao M.-C., Tsai S.-K, Tsou M.-Y., Lee H.-K., Guo W.-Y., Hu J.S.: Paraplegia after delayed detection of inadvertent spinal cord injury during thoracic epidural catheterization in an anesthetized elderly patient. Anesth Analg. 2004;99:580-3.

6. Krzęczko P., Radzikowski K., Chutkowski R., Wódarski B., Molski M., Ulatowski Ł., et al.: Znieczulenie złożone podpajęczynówkowe w odcinku lędźwiowym oraz ciągłe zewnątrzoponowe w odcinku piersiowym do zabiegów rekonstrukcji piersi metodą wolnego płata (DIEP lub SIEA)- doświadczenia własne. Post Nauk Med. 2014;27:328-33.

7. Wnęk W., Zajączkowska R., Sienkiel W., Snela S. :Analgezja pooperacyjna z zastosowaniem ciągłej blokady zewnątrzoponowej w zabiegach stabilizacji kręgosłupa. Przegl Med Uniw Rzesz. 2005;1:49-51.

8. Szebla R., Machała W.: Porównanie skuteczności ciągłego znieczulenia zewnątrzoponowego i przykręgowego podczas operacji płucnych. Anest Inten Terap. 2008:40:152-5.

9. Richardson J., Sabanathan S., Jones J., Shah R.D., Cheema S., Mearns A.J.: A prospective, randomized comparison of perioperative and continuous balanced epidural or paravertebral bupivacaine on post-thoracotomy pain pulmonary function and stress responses. Br J Anaesth. 1999;83:387-92.

10. Davies R.G., Myles P.S., Graham J.M.: A comparison of the analgesic efficacy and side-effects of paravertebral vs epidural blockade for thoracotomy- a systematic review and meta-analysis of randomized trials. Br J Anaesth. 2006;96:418-26.

11. Okajima H., Tanaka O., Ushio M., Higuchi Y., Nagai Y., lijima K., et al.: Ultrasound-guided continuous thoracic paravertebral block provides comparable analgesia and fewer episodes of hipotension than continuous epidural block after lung surgery. J Anesth. 2015;29:373378.

12. Cousins M. J., Carr D.B., Horlocker T.T., Bridenbaugh P. O.: Cousins and Bridenbaugh's neural blockade in clinical anesthesia and pain medicine. 4th Edition. Lippincott Williams and Wilkins; 2009.

13. Idvall E., Hamrin E., Sjöström B., Unosson M.: Quality indicators in postoperative pain management: a validation study. Scand J Caring Sci. 2001;15:331-8.

14. Jaracz K, Wdowczyk K, Górna K: Ocena jakości opieki w aspekcie bólu pooperacyjnego z zastosowaniem polskiej wersji skali klinicznych wskaźników jakości posteepowania z bólem pooperacyinym. Pielegniarstwo Polskie. 2005;19:9-14.

15. Yeung J., Melody T., Kerr A., Naidu B., Middleton L., Tryposkiadis K., et al.: Randomised controlled pilot study to investigate the effectiveness of thoracic epidural and paravertebral blockade in reducing chronic postthoracotomy pain: TOPIC feasibility study protocol. BMJ Open. 2016;6:1-12. https://doi.org/10.1136/bmjopen-2016-012735

16. Ibrahim A.I., Mamdouh N.M.: Comparison between continous thoracic epidural block and continous thoracic paravertebral block for thoracotomy pain relief. Ain Shams J Anesth. 2009:2:16-26.

17. Richardson J., Lönnqvist P.A.: Thoracic paravertebral block. Br J Anaesth. 1998:81:230-238.

18. Ganguly T., Dasgupta C.S., Kar S.K., Goswami A., Bhattacharya C., Som A. et al.: Comparison of postoperative analgesia in thoracotomy patients by thoracic epidural versus paravertebral block with ropivacaine and clonidyne. J Universal Surg. 2015;3:1-7.

19. Szebla R., Machała W., Szebla J.: Znieczulenie przykregowe do torakotomii. Dawkowanie leków znieczulenia przewodowego. Kardiochir Torakochir Pol. 2009;6(2):166-70.

20. Messina M., Boroli F., Landoni G., Bignami E., Dedola E., N'Zepa Batonga J. et al:: A comparison of epidural vs. paravertebral blockade in thoracic surgery. Minerva Anesthesiol. 2009;75:616-21.

21. Pintaric T.S., Potocnik I., Hadzic A., Stupnik T., Pintaric M., Jankovic V.N. Comparison of continuous thoracic epidural with paravertebral block on perioperative analgesia and hemodynamic stability in patients having open lung surgery. Reg Anesth Pain Med. 2011:36:256-60.

22. Komatsu T., Sowa T., Takahashi K., Fujinaga T.: Paravertebral block as a promising analgesic modality for managing post-thoracotomy pain. Ann Thorac Cardiovasc Surg. 2014;20:113-6.

23. Katayama T., Hirai S., Kobayashi R., Hamaishi M., Okada T., Mitsui N.: Safety of the paravertebral block in patients ineligible for epidural block undergoing pulmonary resection. Gen Thorac Cardiovasc Surg. 2012;60:811-4.

24. Tsuboshima K., Nagata M., Wakahara T., Matoba Y., Nishio W., Maniwa Y.: Novel paravertebral block during single-incision thoracoscopic surgery for primary spontaneous pneumothorax. Gen Thorac Cardiovasc Surg. 2016;64:58-61.

25. Elsayed H., McKevith J., McShane J., Scawn N.: Thoracic epidural or paravertebral catheter for analgesia after lung resection: Is the outcome different? J Cardiothorac Vasc Anesth. 2012;26:78-82. 